\title{
Myeloid Sarcoma "en plaque” Disguised as Acute Subdural Hematoma
}

\author{
Dragos Catana, Boleslaw Lach, Aleksa Cenic
}

Key words: emergency, hemorrage - cerebral, neuro-oncology, neuropathology, neurosurgery, soft tissue tumors

Intracranial myeloid sarcoma (MS) is a rare hematological malignancy predating or complicating the course of myeloid leukemia. It can mimic the clinical and radiologic presentation of other pathological lesions of the central nervous system. We describe a 37 year old male with chronic myeloid leukemia (CML) who developed subdural MS "en plaque" that mimicked an acute subdural hematoma at presentation. Only four instances of this clinical and radiologic pitfall have ever been reported.

\section{Clinical history}

A 37 year old male inpatient at a peripheral hospital was transferred to our neurosurgical center for rapidly deteriorating neurological status secondary to a presumed acute subdural hematoma. He presented to the local hospital for a three week persistent headache and was undergoing rescue therapy with hydroxyurea for relapse of CML. He previously failed bone marrow transplantation, donor leukocyte infusion, and second generation tyrosine kinase inhibitors. There was no history of recent trauma or anticoagulation; however grade 1 thrombocytopenia was present. One unit of adult platelets was transfused prior to hospital transfer. On initial assessment the patient was sedated, intubated and mechanically ventilated. Off sedation he was able to localize painful stimulus without eye opening. The left pupil was four $\mathrm{mm}$ and non-reactive, the right was three $\mathrm{mm}$ and reactive. The left toes were upgoing on plantar stimulation. Brainstem reflexes were intact. The Glasgow Coma Scale (GCS) was established at 6T, acutely deteriorating from a GCS of 15 recorded the previous day. The remainder of the physical examination was unremarkable.

Laboratory investigations revealed leukocyte count of $158.1 \times 10^{9}$ with $31.1 \%$ blasts, hemoglobin of $118 \mathrm{~g} / \mathrm{L}$, platelets of $96 \times 10^{9}$ after one unit of adult platelets transfusion. The coagulation, electrolyte and renal function profiles were unremarkable. Unenhanced CT of the head showed left convexity hyperdense crescent shaped mass underlying the dura and measuring $1.7 \mathrm{~cm}$ in its thickest portion, associated with midline shift greater than $1.0 \mathrm{~cm}$ and early uncal herniation (Fig. 1A). Interestingly, a gadolinium-enhanced magnetic resonance imaging (MRI) of the head was performed two days prior to transfer and was reported as a left-sided subdural hematoma with leptomeningeal enhancement by the local radiologist. The MRI images were not available for review at our institution.

In light of the typical computed tomography (CT) findings and MRI report, the possibility of occult trauma in the context of chronic thrombocytopenia was considered in this acutely deteriorating patient. At the time of initial admission his Karnofsky score was 80 . The patient was taken for emergent fronto-temporal craniectomy and evacuation of subdural collection. Bone flap removal revealed a distended and discolored bluish dura. Following the cruciate durotomy, a dense grey-tan extra-axial tissue was observed. There was no hematoma. The mass was adherent to the dural layer extending anteriorly, posteriorly and medially toward the falx. The tumorous lesion was gently dissected off the pial surface and removed in piecemeal fashion (Fig. 1B). Although the brain was decompressed as the lesion was resected, it began to swell rapidly and the remainder of the lesion was cauterized before duraplasty and scalp closure. The patient was sent to the intensive care unit and treated with hypertonic solution and dexamethasone. Despite maximum medical therapy he developed fixed and dilated pupils and gradually lost brainstem reflexes within hours of the surgery. $\mathrm{He}$ was pronounced dead the following day.

Microscopic examination of the subdural mass revealed a dense population of non-cohesive undifferentiated hematopoietic cells displaying frequent mitotic figures and apoptotic nuclei (Fig. 2A). Scattered macrophages with cellular debris, and necrotic cells created a starry-sky pattern to the tissues. The neoplastic cells were uniformly and strongly positive for myeloperoxidase (Fig 2B), and less intense in $\mathrm{BCl} 2$. The tumour was negative for CD3, CD4, CD8, CD20, CD79a and PAX5. A granulocytic sarcoma was diagnosed.

\section{DISCUSSION}

Granulocytic sarcoma represents a soft tissue mass arising from the extramedullary proliferation of immature myeloid cells. Progenitors include myeloblasts, myelocytes, and promyelocytes. Historically it was known as "chloroma" due to the green tint conferred by the presence of heme rich myeloperoxidase. However, the combination of varying amounts of this enzyme and molecular oxidation state may result in a white, gray, and brown appearance in approximately one third of the cases. ${ }^{3}$ The 2008 WHO tumour classification nomenclature has unified these and other terms in favour of "myeloid sarcoma" to better account its histogenesis. ${ }^{8}$

From the Division of Neurosurgery (DC, AC); Department of Molecular Medicine and Pathology (BL), McMaster University, Hamilton, Ontario, Canada.

Received April 20, 2015. Final Revisions Submitted October 6, 2015.

Correspondence to: Dragos Catana, McMaster University, 237 Barton St. East, 8N06

Hamilton, ON, L8L 2X2. Email: dragos.catana@medportal.ca 
(A)

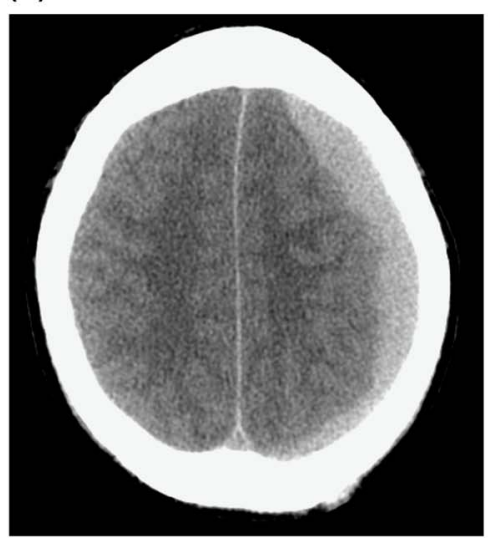

(B)

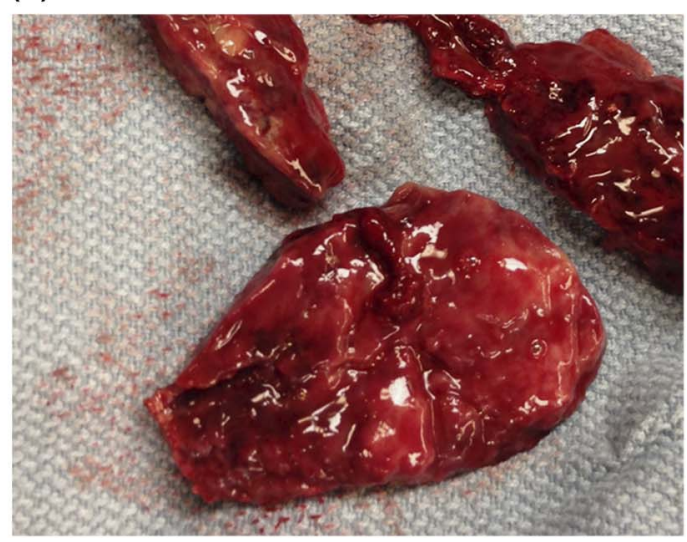

Figure 1: Unenhanced CT head (A); Intra-operative photograph of subdural mass (B).

(A)

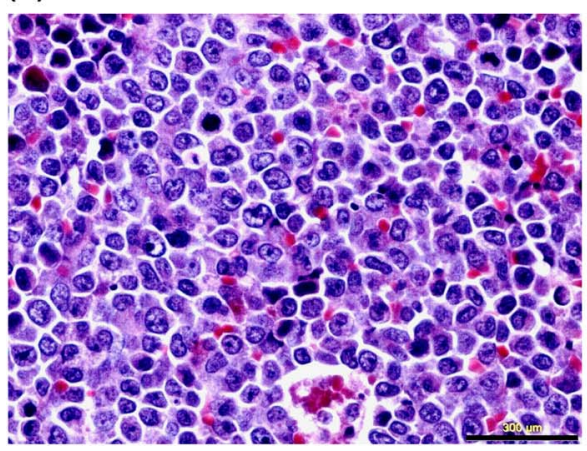

(B)

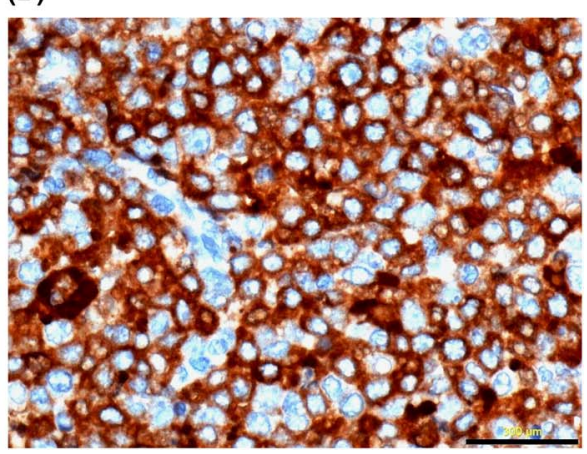

Figure 2: Hematoxylin and eosin stained section demonstrating poorly differentiated neoplastic cells, scattered mitotic figures and apoptotic nuclei (A). Strong immunoreaction for myloperoxidase in tumour cells $(\boldsymbol{B})$.

Table 1: Myeloid Sarcoma mimicking SDH reported in literature

\begin{tabular}{|c|c|c|c|c|c|c|c|c|}
\hline Year & Authors & Age & Sex & Histology & $\begin{array}{l}\text { Underlying } \\
\text { malignancy }\end{array}$ & Trauma & Treatment & Survival \\
\hline 2012 & Mallory GM, Lanzino $\mathrm{G}^{5}$ & 45 & $F$ & myeloid sarcoma & AML & No & $\begin{array}{l}\text { burr evacuation, radiotherapy, } \\
\text { chemotherapy }\end{array}$ & 6 months \\
\hline 2011 & $\begin{array}{l}\text { O'Brien CE, Saratsis AM, Voyadzis } \\
\text { JM }^{6}\end{array}$ & 34 & M & $\begin{array}{l}\text { granulocytic } \\
\text { sarcoma }\end{array}$ & CML & No & resection, leukophoresis & 2 days \\
\hline 2010 & Yilmaz S, Tanyeli $\mathrm{A}^{9}$ & 12 & $\mathrm{~F}$ & $\begin{array}{c}\text { granulocytic } \\
\text { sarcoma }\end{array}$ & AML & No & resection, chemotherapy & 3 months \\
\hline 2005 & $\begin{array}{l}\text { Smidt MH, de Bruin HG, van't Veer } \\
\mathrm{MB}^{7}\end{array}$ & 63 & M & $\begin{array}{l}\text { granulocytic } \\
\text { sarcoma }\end{array}$ & AML & No & $\begin{array}{l}\text { biopsy steroids chemotherapy } \\
\text { radiotherapy }\end{array}$ & 10 months \\
\hline
\end{tabular}

SDH: subdural hematoma, AML: acute myeloid leukemia, CML: chronic myeloid leukemia

Myeloid sarcoma can theoretically occur in any organ. Most common sites of involvement are the skin, lymph nodes, mediastinum, pelvic organs, and orbits. ${ }^{2}$ Intracranial involvement is typically epidural, making the subdural space an exceedingly rare site of occurrence. Although isolated cerebral myeloid sarcomas have been described, these lesions arise most commonly in the context of hematologic dysplastic disorders such as acute myeloid leukemia, chronic myeloid leukemia or other myeloproliferative disorders. Less commonly these lesions can precede hematologic conditions by several months or even years. The pediatric population accounts for $60 \%$ of the cases, perhaps due to its higher incidence of hematologic malignancy. Modern day treatment strategies have increased the number of adult patients in remission, thus raising the likelihood of encountering extra-medullary relapses such as MS in current and future practice. ${ }^{2}$ Some authors suggest bone marrow transplantation as a 
risk factor for extramedullary proliferation. ${ }^{2}$ It remains unclear whether this observation is truly treatment induced or represents a natural disease progression.

Imaging of the central nervous system usually reveals an extra-axial mass isodense or hyperdense to brain parenchyma on unenhanced CT. These lesions tend to be hypo- or isointense on T1-weighted MRI and iso- or hyperintense on T2-weighted sequences. Contrast administration results in avid homogeneous enhancement, a distinguishing feature from subdural hematomas. ${ }^{3}$ The constellation of these features were present in this patient's MRI, however they could not be appreciated since the images were not available for review at our institution. Pathologic diagnosis relies on immunohistochemistry demonstrating reactions for myeloperoxidase. Myelocytes may also be positive for CD33 and CD117. ${ }^{4}$ Absent immunoreactivity for CD3, CD4, CD20, CD79a and PAX5 excluded extranodal lymphoproliferative conditions in our patient.

It is exceedingly rare for such lesions to present with clinical and radiologic findings typical of an acute subdural hematoma. Our literature review reveals four similar cases (Table 1). All of them had a concurrent hematologic malignancy and no clear history of head trauma. Evidence regarding optimal treatment of these patients is scarce; however chemotherapy alone and in combination with irradiation has been shown favorable in retrospective reviews. ${ }^{1}$ Earlier recognition and aggressive medical treatment of this patient's condition may have averted the acute neurologic deterioration and surgical intervention. Contrast-enhanced MRI showing homogeneous enhancement virtually excludes the presence of a hematoma and may be considered sufficient evidence to pursue these treatments in the context of underlying myeloproliferative disorders. Neurosurgical intervention is reserved for rapidly deteriorating patients in the setting of significant mass effect or in ambiguous clinical scenarios requiring tissue diagnosis.

\section{ConCLusion}

Hematologic malignancies and their treatments predispose patients to intracerebral hemorrhage, however the astute clinician is wise to be mindful of other etiologies that may mimic their clinical and radiologic presentation. Magnetic resonance imaging plays a crucial role in the clarification of the underlying etiology. Our experience underscores the importance of considering myeloid sarcoma in the differential diagnosis of atypical subdural hematoma in patients with underlying hematologic disorders.

\section{Disclosure}

Dragos Catana, Boleslaw Lach, and Aleksa Cenic do not have anything to disclose.

\section{REFERENCES}

1. Batia A, Koren-Michowitz M. Myeloid sarcoma: current approach and therapeutic options. Ther Adv Hematol. 2011; 2:309-16.

2. Clark WB, Strickland SA, Barrett AJ, Savani BN. Extramedullary relapses after allogeneic stem cell transplantation for acute myeloid leukemia and myelodysplastic syndrome. Haematologica. 2010;95:860-3.

3. Guermazi A, Feger C, Rousselot P, et al. Granulocytic sarcoma (chloroma) imaging findings in adults and children. AJR Am J Roentgenol. 2002;178:319-25.

4. Klco J. M., et al. State of the art in myeloid sarcoma. Int J Lab Hematol. 2011;33:555-65.

5. Mallory GM, Van Gompel JJ, Rabinstein AA, Fugate JE, Lanzino G. Wolf in sheep's clothing: acute chloroma disguised as a subdural hematoma. Neurocrit Care. 2012;16:148-50.

6. O'Brien CE, Saratsis AM, Voyadzis JM. Granulocytic sarcoma in a patient with blast crisis mimicking a chronic subdural hematoma. J Clin Oncol. 2011;29:e569-71.

7. Smidt MH, de Bruin HG, van't Veer MB, van den Bent MJ. Intracranial granulocytic sarcoma (chloroma) may mimic a subdural hematoma. J Neurol. 2005;252:498-9.

8. Tefferi A, Thiele J, Vardiman JW. The 2008 World Health Organization classification system for myeloproliferative neoplasms. Cancer. 2009;115:3842-7.

9. Yilmaz S, Bayram I, Erbey F, Aslamaci D, Tanyeli A. Can any cerebral mass or hematoma be leukemia? Chloroma. Nobel Med. 2012;8:118-20. 